\title{
Incidence of Hyperglycemia/Secondary Diabetes in Women who have Undergone Curative Chemotherapy for Breast Cancer: First Study from India
} \author{
Manjeshwar Shrinath Baliga ${ }^{3}$ \\ ${ }^{1}$ Department of Radiation Oncology, Mangalore Institute of \\ Oncology, Mangalore, Karnataka, India \\ ${ }^{2}$ Department of Medical Oncology, Mangalore Institute of \\ Oncology, Mangalore, Karnataka, India \\ ${ }^{3}$ Research Unit, Mangalore Institute of Oncology, Mangalore, \\ Karnataka, India
}

Suresh Rao ${ }^{1}$ Krishna Prasad ${ }^{2}$ Soniya Abraham ${ }^{3}$ Thomas George ${ }^{3} \quad$ Supreeth Kakkaje Chandran ${ }^{3}$

Address for correspondence Manjeshwar Shrinath Baliga, Research Unit, Mangalore Institute of Oncology, Pumpwell, Mangalore, Karnataka 575002,India (e-mail: msbaliga@gmail.com).

\section{South Asian J Cancer 2020;9:130-135.}

\section{Abstract}

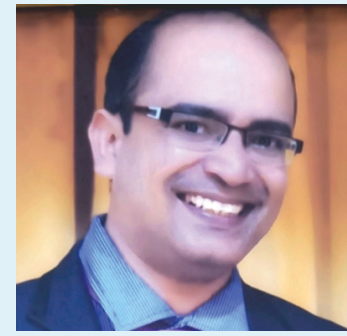

Dr. Manjeshwar Shrinath Baliga
Keywords

- breast cancer

- chemotherapy

- secondary diabetes
Purpose Development of cancer chemotherapy treatment-induced hyperglycemia/ diabetes (secondary diabetes) is a major problem and has never been reported from India. The present study was planned to ascertain this in women undergoing curative chemotherapy for their breast cancer.

Materials and Methods This was a retrospective chart-based study and was conducted in a cancer specialty hospital. The information on women who were nondiabetic at the start of the treatment was collected from the files. Details on cancer diagnosis, domicile, body mass index (BMI), type of diet, marital status, number of children, and previous history of diabetes if any were considered. The blood glucose levels before surgery and after the completion of radiotherapy were considered. World Health Organization (WHO) guidelines for diabetes were considered. The data were subjected to frequency and percentage and analyzed using Chi-square test. Association between the demographic details and development of Hyperglycemia or secondary diabetes or prediabetes was done using the Pearson's correlation analysis. $p<0.05$ was considered as statistically significant.

Results A total of 474 cases were included in accordance with the inclusion criteria. The results indicated that by the end of the radiation treatment, $24.89 \%$ were prediabetic, $10.97 \%$ were diabetic after being in prediabetic stage, $8.22 \%$ became diabetic without going through a prediabetic stage, and that $55.91 \%$ did not develop either prediabetic or diabetic condition. Analysis of development of secondary diabetes and prediabetes with BMI $(p<0.0001)$ and age $(p<0.024)$ showed a strong correlation and was significant.

Conclusion To the best of the authors' knowledge, this is the first study from India, and the results indicate that the development of secondary diabetes in women undergoing curative chemotherapy is high. Attempts are underway to ascertain the cause for the development and how it can be mitigated.
How to cite this article: Rao S, Prasad K, Abraham S, George T, Chandran SK, Baliga MS. Incidence of Hyperglycemia/Secondary Diabetes in Women who have Undergone Curative Chemotherapy for Breast Cancer: First Study from India. South Asian J Cancer 2020; 9(3):130-135.

DOI https://doi.org/10.1055/s-0041-1723104 ISSN 2278-330X.
(C) 2020. MedIntel Services Pvt Ltd.

This is an open access article published by Thieme under the terms of the Creative Commons Attribution-NonDerivative-NonCommercial-License, permitting copying and reproduction so long as the original work is given appropriate credit. Contents may not be used for commercial purposes, or adapted, remixed, transformed or built upon. (https://creativecommons.org/licenses/by-nc-nd/4.0/).

Thieme Medical and Scientific Publishers Private Ltd A-12, Second Floor, Sector -2, NOIDA -201301, India 


\section{Introduction}

Global reports indicate that in women, the incidence of breast cancer is on a rise, and that today, it is the most common malignancy in many parts of the world. ${ }^{1}$ To substantiate this recent global data obtained for the year 2012 suggests that, with an estimated 1.67 million new cancer cases diagnosed, breast cancer amounts to almost a quarter (25\%) of all the reported cancer numbers. ${ }^{1}$ What is more worrying is that reports also suggest that when compared with the more developed countries, women from the less developed countries have slightly more number of cases, indicating a disparity in the incidence and that a rise in the case of cancers in underprivileged areas may affect the society at large. ${ }^{1,2}$

Conventionally, depending on the stage and the general health of the women, breast cancer is treated with surgery, chemotherapy, and radiotherapy. ${ }^{3}$ In addition to these modalities, depending on the epidermal growth factor receptor encoded by the ERBB2 or human epidermal growth factor receptor 2 (HER2) gene, immunologicals like trastuzumab (herceptin) may also be used to slow down the growth of the cancer. ${ }^{3}$ Furthermore, depending on the estrogen receptor (ER) status (ER positive), modulators like tamoxifen may also be used to inhibit the estrogenic effects responsible for cancer cell growth or proliferation. ${ }^{4}$ However, the uses of various classes of anticancer and supportive pharmacological agents (such as antiemetics, analgesics, and steroids) are known to have adverse effects and affect the quality of life in the cancer survivors.

Studies have shown that some women who were nondiabetic (normoglycemic) at the start of the cancer chemotherapy develop treatment-induced diabetes, also known as secondary diabetes. ${ }^{5}$ The factors attributed to this include the stress induced by the cytotoxic chemotherapeutic agents and the use of the dexamethasone, important in preventing chemotherapy-induced nausea and vomiting during the course of the treatment. ${ }^{5,6}$ Previous studies have shown that glucocorticoid therapy, cisplatin, everolimus, docetaxel, and androgen deprivation therapy can contribute to uncontrolled hyperglycemia. ${ }^{7}$ Administration of steroid to mitigate emesis and inflammatory reactions is shown to induce steroid-induced hyperglycemia and diabetes in people undergoing therapy for cancer. ${ }^{8-15}$

Previous studies have shown that almost $20 \%$ of nondiabetic cancer patients develop steroid-induced diabetes after antiemetic dexamethasone therapy. ${ }^{5}$ Although not clear, these negative effects of steroids are attributed to myriad factors, the most important being increased insulin resistance and glucose intolerance, reduced $\beta$-cell mass from $\beta$-cell dysfunction, and increased hepatic insulin resistance. ${ }^{16-18}$ In this retrospective chart-based study, an attempt was made at understanding the incidence of development of secondary diabetes in the normoglycemic women who underwent surgery, chemotherapy, and radiation.

\section{Materials and Methods}

This was a retrospective chart-based study which was conducted, after obtaining the permission from the institutional ethics committee (MIOIEC/2019/15). The medical record files of women, who had undergone surgical treatment, either radical or simplified mastectomy, followed by curative chemotherapy treatment, which includes a combination of drugs like anthracycline, paclitaxel/docetaxel alone or combined with other drugs, second-line chemotherapy regimen (such as capecitabine, gemcitabine, platinums, and vinorelbine) endocrine therapy, and HER2-targeted therapies, were considered.

The blood glucose levels are always evaluated before surgery during fitness evaluation, before the commencement of each chemotherapy cycle, before and after the completion of radiotherapy, and at 1 to 3 months' intervals after the completion of the radiotherapy. The criteria considered to be diabetic was in accordance with the World Health Organization (WHO) guidelines of 1999 which categorizes an individual with fasting plasma glucose $\geq 7.0 \mathrm{mmol} / \mathrm{L}$, a random plasma glucose $\geq 11.1 \mathrm{mmol} / \mathrm{L}$, or a 2-hour plasma glucose $\geq 11.1 \mathrm{mmol} / \mathrm{L}$ during an oral glucose tolerance test as diabetic. The standard practice for management of diabetes is in accordance with standard guideline $\mathrm{e}^{19,20}$ and includes dietary measures and prescription of oral hypoglycemic medication, depending on the clinical condition and the judgment of physicians.

The study time point considered was from January 2017 to December 2018. The inclusion criteria included collection of data only from women, between the ages of 20 to 80 , who were not diabetics and completed the planned treatment of surgery, chemotherapy, and radiotherapy during the study time point. The exclusion criteria included men who were treated for breast cancer, women known to be diabetics (Type 1 and/or Type 2) and were under medication for it, women who were newly diagnosed to have diabetes before the start of the treatment (during their fitness test prior to surgery), women who received neoadjuvant therapy before surgery, and women who discontinued treatment. The data were anonymized by the in charge of medical records department (MRD) and contained data on demographic and clinical aspects.

Three research assistants extracted the data from the provided medical records. The demographic details such as age at the time of breast cancer diagnosis, domicile, body mass index (BMI), type of diet, marital status, number of children, previous history of diabetes, hypertension, and menopausal status, as well as clinical data such as the histopathological details (tumor, node, metastasis [TNM] staging, hormonal receptor status [estrogen, progesterone] and HER2/neu status ascertained by immunohistochemical methods and fluorescence in situ hybridization assay to further validate the HER2-positive status), were collected when available in the files. The details on when hyperglycemia/secondary diabetes developed, and treatment discontinued, were entered into Microsoft Excel by the research assistants. Only those data that met the inclusion criteria were entered into the Excel sheet.

\section{Statistical Analysis}

The data entered into Microsoft excel were exported to SPSS version 23, IBM Corp, NY, USA for analysis. The descriptive 
data were subjected to frequency and percentage and Chisquare test. The association between the demographic details and development of and the occurrence of secondary diabetes or prediabetes conditions was done using the Pearson's correlation analysis. A $p$ value of $<0.05$ was considered significant.

\section{Results}

During the study time point considered from January 2017 to December 2018, a total of 535 cases of breast cancer were treated. In these, 61 cases were not included as they did not meet the inclusion criteria. A total of 474 cases were observed to satisfy the inclusion criteria and included for the analysis. The demographic details such as age at the time of cancer diagnosis domicile (rural/urban), BMI, type of diet, marital status, and number of children while the clinical data on the TNM stage, ER, progesterone receptor (PR), and HER2 status are represented in -Table 1.

With regard to the details on the development of secondary diabetes, the results indicated that by the end of the radiation treatment, $24.89 \%$ (118/474) were prediabetic, $10.97 \%$ (52/474) were diabetic after being in prediabetic stage, $8.22 \%$ (39/474) became diabetic without going through a prediabetic stage, and 55.91 (265/474) did not develop either prediabetic or diabetic condition (-Table 2). Analysis of development of secondary diabetes and prediabetes with BMI $(p<0.0001)$ and age $(p<0.024)$ showed a strong correlation and was significant ( - Table 3 ).

The details indicated that most of the women who developed prediabetes and diabetes were in the age group 41 to 60 and 41 to 70 , respectively, and a trend was observed $(p=0.084)$ ( - Table 3 ). With regard to BMI, the observations suggest that many women with BMI more than 22 developed prediabetes (51.7\%) and diabetes $(56 \%)$ and was statistically significant $(p=0.001)$. With regard to the tumor stage and place of domicile, there was no association. With relation to the hormone receptor (ER and PR) status, it was observed that $69.1 \%$ and $60.8 \%$ developed prediabetes, while 60.5 and $48.1 \%$ developed diabetes and was significant ( $p=0.01$ and $p=0.016$, respectively) (-Table 3). However, with regard to HER2 status, 62.6\% and $68.8 \%$ developed prediabetes and diabetes, respectively $(p=0.044)(-$ Table 2$)$.

\section{Discussion}

Recent data from India indicate that the incidence of breast cancer is on the rise, and that in the near future, it will be a major health issue. ${ }^{2}$ Reports also do suggest that the incidence of diabetes is also high and that India has the second largest population (69.2 million) with diabetes. ${ }^{21,22}$ From a clinical perspective, although different in the pathogenesis and disease progression, both ailments share the etiology and signaling pathways ${ }^{23}$ and aspects such as old age, obesity, genetic predisposition, sedentary lifestyle, and chronic
Table 1 The demographic and tumor pathology details of the study participants

\begin{tabular}{|c|c|}
\hline & Count (\%) \\
\hline \multicolumn{2}{|l|}{ Age code } \\
\hline $18-30$ & $10(2.1)$ \\
\hline $31-40$ & 85 (17.9) \\
\hline $41-50$ & $157(33.1)$ \\
\hline $51-60$ & $128(27.0)$ \\
\hline $61-70$ & $76(16.0)$ \\
\hline Above 70 & $18(3.8)$ \\
\hline Total & $474(100.0)$ \\
\hline \multicolumn{2}{|l|}{ BMI code } \\
\hline$<18$ & $43(9.1)$ \\
\hline $18-22$ & $251(53.0)$ \\
\hline$>22$ & $180(38.0)$ \\
\hline Total & $474(100.0)$ \\
\hline \multicolumn{2}{|l|}{ Place code } \\
\hline Village & $45(9.5)$ \\
\hline Town & 178 (37.6) \\
\hline City & $251(53.0)$ \\
\hline Total & $474(100.0)$ \\
\hline \multicolumn{2}{|l|}{ Tumor T } \\
\hline Tumor T1 & $32(6.8)$ \\
\hline Tumor T2 & $220(47.0)$ \\
\hline Tumor T3 & $119(25.4)$ \\
\hline Tumor T4 & $97(20.7)$ \\
\hline Total & $468(100.0)$ \\
\hline \multicolumn{2}{|l|}{ ER code } \\
\hline Negative & 175 (44.5) \\
\hline Positive & $218(55.5)$ \\
\hline Total & $393(100.0)$ \\
\hline \multicolumn{2}{|l|}{ PR code } \\
\hline Negative & $202(51.4)$ \\
\hline Positive & 191 (48.6) \\
\hline Total & $393(100.0)$ \\
\hline \multicolumn{2}{|l|}{ HER code } \\
\hline Negative & $250(66.1)$ \\
\hline Positive & 113 (29.9) \\
\hline Equivocal & $15(4.0)$ \\
\hline Total & $378(100.0)$ \\
\hline
\end{tabular}

Abbreviations: BMI, body mass index; ER, estrogen receptor; HER, human epidermal growth factor receptor; PR, progesterone receptor.

inflammation have a forbearing on the development of these ailments. ${ }^{14}$ In addition, to these reports also suggest that females afflicted with breast cancer have an increased risk of developing diabetes and that this can have an adverse effect on their general health and quality of life. 
Table 2 Information on the development of the prediabetic and diabetic condition

\begin{tabular}{|c|c|c|}
\hline Our observation & $n(\%)$ & Percentage (\%) \\
\hline Normal to normal & $265(55.91)$ & \\
\hline $\begin{array}{l}\text { Normal to } \\
\text { prediabetic }\end{array}$ & 118 (24.89) & \\
\hline $\begin{array}{l}\text { Normal to predia- } \\
\text { betic to diabetic }\end{array}$ & $52(10.97)$ & 10.97 \\
\hline $\begin{array}{l}\text { Normal to directly } \\
\text { diabetic }\end{array}$ & $39(8.22)$ & 8.22 \\
\hline Total number is 474 & $474(100)$ & $\begin{array}{l}\text { By the end of radio- } \\
\text { therapy } 19.20 \% \text { have } \\
\text { developed diabetes }\end{array}$ \\
\hline
\end{tabular}

In this study, it was observed that by the end of the radiation treatment, 55.91\% did not develop either prediabetic or diabetic condition. Of the remaining $44.01 \%$ of the study population, $24.89 \%$ were prediabetic and $19.19 \%$ were diabetic (-Table 2). Previous studies from around the world have shown that $9.7 \%^{23}$ to $13 \%{ }^{24}$ elderly women developed secondary diabetes. The most important aspect here with is that when compared with previous studies, majority of the women who developed diabetes were in the age group of 41 to 50 years ( - Table 3 ). To substantiate this, community-based studies conducted with the rural population of Mangalore have shown that $29.6 \%$ of the women were diabetic and that this was higher than in men (25.4\%). ${ }^{25}$ In addition, reports from other parts of Karnataka have also shown that the prevalence of diabetes in females were more than in men. ${ }^{26,27}$ The most possible reason for this high incidence is that most women in the study area were homemakers with a sedentary lifestyle, a known factor associated with development of type 2 diabetes.

The other important aspect observed was that 56.0\% and $51.7 \%$ of the women with BMI more than 22 developed diabetes and prediabetic conditions. Obesity is associated with increased risk of diabetes, and a recent case-control study with diabetics published from the study area has shown that $55 \%$ of them had BMI over $25 \mathrm{~kg} / \mathrm{m}^{2}$ as compared with $22 \%$ of controls and that this association was statistically significant $(p<0.05) .{ }^{28}$ These observations are in agreement to the results published by Mohan et al where it is clearly indicated that BMI had a strong association for all cardiometabolic risk factors for both diabetes mellitus (DM) and prediabetes and ranged from 22.7 to $23.8 \mathrm{~kg} / \mathrm{m}^{2}$ for women. ${ }^{29}$

In the study, it was also observed that irrespective of the place of domicile, there was no significant difference, indicating that place of residence does not play a role in the development of Hyperglycemia/secondary diabetes. Only possible explanation that can be offered for this observation is that the per capita income of people living in the study area is in the higher bracket and previous studies from India have shown that states with higher per capita gross domestic product seemed to have a higher prevalence of diabetes. ${ }^{30}$ Further reports ${ }^{30}$ also suggest that diabetes prevalence was higher in people with lower socioeconomic status and the observations of Padmanabha et al substantiate this. ${ }^{25}$
Table 3 Chi-square calculation to ascertain the association between various demographic features with prediabetes and diabetes in the study subjects

\begin{tabular}{|c|c|c|c|c|}
\hline & \multicolumn{3}{|c|}{ Count (\%) } & \multirow[b]{2}{*}{$p$-Value } \\
\hline & $\begin{array}{l}\text { Normal to } \\
\text { normal }\end{array}$ & $\begin{array}{l}\text { Normal to } \\
\text { pre-DM }\end{array}$ & $\begin{array}{l}\text { Normal } \\
\text { to DM }\end{array}$ & \\
\hline \multicolumn{5}{|l|}{ Age code } \\
\hline $18-30$ & $10(3.8)$ & $0(0.0)$ & $0(0.0)$ & \multirow[t]{7}{*}{0.084} \\
\hline $31-40$ & $54(20.4)$ & $18(15.3)$ & $13(14.3)$ & \\
\hline $41-50$ & 82 (30.9) & $42(35.6)$ & $33(36.3)$ & \\
\hline $51-60$ & 74 (27.9) & $34(28.8)$ & $20(22.0)$ & \\
\hline $61-70$ & $35(13.2)$ & $21(17.8)$ & $20(22.0)$ & \\
\hline Above 70 & $10(3.8)$ & $3(2.5)$ & $5(5.5)$ & \\
\hline Total & $265(100.0)$ & $118(100.0)$ & $91(100.0)$ & \\
\hline \multicolumn{5}{|l|}{$\mathrm{BMI}$} \\
\hline$<18$ & 31 (11.7) & $8(6.8)$ & $4(4.4)$ & \multirow[t]{4}{*}{0.0001} \\
\hline $18-22$ & $166(62.6)$ & 49 (41.5) & 36 (39.6) & \\
\hline$>22$ & $68(25.7)$ & $61(51.7)$ & $51(56.0)$ & \\
\hline Total & $265(100.0)$ & $118(100.0)$ & $91(100.0)$ & \\
\hline \multicolumn{5}{|l|}{ Place } \\
\hline Village & $30(11.3)$ & $12(10.2)$ & $3(3.3)$ & \multirow[t]{4}{*}{0.102} \\
\hline Town & $93(35.1)$ & $51(43.2)$ & $34(37.4)$ & \\
\hline City & $142(53.6)$ & 55 (46.6) & $54(59.3)$ & \\
\hline Total & $265(100.0)$ & $118(100.0)$ & $91(100.0)$ & \\
\hline \multicolumn{5}{|l|}{ Tumor stage } \\
\hline Tumor T1 & $19(7.2)$ & $6(5.1)$ & $8(8.9)$ & \multirow[t]{5}{*}{0.57} \\
\hline Tumor T2 & $124(47.1)$ & $52(44.4)$ & $44(48.9)$ & \\
\hline Tumor T3 & 65 (24.7) & $34(29.1)$ & $21(23.3)$ & \\
\hline Tumor T4 & 55 (20.9) & 25 (21.4) & 17 (18.9) & \\
\hline Total & $263(100.0)$ & $117(100.0)$ & $90(100.0)$ & \\
\hline \multicolumn{5}{|l|}{ ER status } \\
\hline Negative & $113(52.6)$ & $30(30.9)$ & $32(39.5)$ & \multirow[t]{3}{*}{0.001} \\
\hline Positive & $102(47.4)$ & $67(69.1)$ & $49(60.5)$ & \\
\hline Total & $215(100.0)$ & $97(100.0)$ & 81 (100.0) & \\
\hline \multicolumn{5}{|l|}{ PR status } \\
\hline Negative & $122(56.7)$ & $38(39.2)$ & 42 (51.9) & \multirow[t]{3}{*}{0.02} \\
\hline Positive & $93(43.3)$ & $59(60.8)$ & $39(48.1)$ & \\
\hline Total & $215(100.0)$ & $97(100.0)$ & $81(100.0)$ & \\
\hline \multicolumn{5}{|l|}{ HER2 status } \\
\hline Negative & $138(66.7)$ & $57(62.6)$ & $55(68.8)$ & \multirow[t]{3}{*}{0.044} \\
\hline Positive & $69(33.3)$ & $34(37.4)$ & $25(31.3)$ & \\
\hline Total & $207(100.0)$ & $91(100.0)$ & $80(100.0)$ & \\
\hline
\end{tabular}

Abbreviations: BMI, body mass index; DM, diabetes mellitus; ER, estrogen receptor; HER2, human epidermal growth factor receptor 2; PR, progesterone receptor.

With regard to association between tumor pathological details and development of diabetes, an association was not seen with the TNM stage (0.57), while it was significant for ER positive (0.001), PR positive (0.02), and HER2 negative status 
(0.04). The authors are unaware of any reports that suggest the association between the ER, PR, and HER2 status with development of Hyperglycemia/secondary diabetes. In lieu of these observations, it is imperative that a large study from different population is required to ascertain the role of these three molecular markers in the development of type II diabetes. In addition to this, suitable preclinical studies to validate the role of ER, PR, and HER2 status in the development of type II DM is required to answer the mechanistic basis for the observed phenomenon.

\section{Conclusion}

Our data for the first time indicate that the incidence of development of cancer treatment-induced hyperglycemia/ diabetes is high in the Indian women being treated for their breast cancer from this part of India. The observations that $24.89 \%$ were prediabetic and $10.97 \%$ diabetic at the end of the radiation treatment indicate that development of diabetes in the breast cancer survivors can be a major issue. The reluctance of patients for a regular followup care on completion of treatment is a major hurdle in asertaining the magnanimity of the problem. Studies are underway to find the cause for development of hyperglycemia/ secondary diabetes and on how they can be mitigated. Efforts are also underway to see the incidence of cancer metastasis/recurrence and long term effect of development of treatment induced diabetes and other metabolic syndromes in these patients.

Funding
Nil.
Conflict of Interest
None declared.

\section{References}

1 Ferlay J, Soerjomataram I, Dikshit R, et al. Cancer incidence and mortality worldwide: sources, methods and major patterns in GLOBOCAN 2012. Int J Cancer 2015; 136(5):E359-E386

2 Malvia S, Bagadi SA, Dubey US, Saxena S. Epidemiology of breast cancer in Indian women. Asia Pac J Clin Oncol 2017; 13(4):289-295

3 World Health Organization, Guidelines for Management of Breast Cancer. EMRO Technical Publications Series 31. Geneva, Switzerland: World Health Organization; 2006

4 Chang M. Tamoxifen resistance in breast cancer. Biomol Ther (Seoul) 2012;20(3):256-267

5 Jeong Y, Han HS, Lee HD, et al. A pilot study evaluating steroid-induced diabetes after antiemetic dexamethasone therapy in chemotherapy-treated cancer patients. Cancer Res Treat 2016;48(4):1429-1437

6 Hwangbo Y, Lee EK. Acute hyperglycemia associated with anti-cancer medication. Endocrinol Metab (Seoul) 2017;32(1): 23-29

7 Ariaans G, de Jong S, Gietema JA, Lefrandt JD, de Vries EG, Jalving M. Cancer-drug induced insulin resistance: innocent bystander or unusual suspect. Cancer Treat Rev 2015; 41(4):376-384
8 Vidler J, Rogers C, Yallop D, et al. Outpatient management of steroid-induced hyperglycaemia and steroid-induced diabetes in people with lymphoproliferative disorders treated with intermittent high dose steroids. J Clin Transl Endocrinol 2017;9:18-20

9 Healy SJ, Nagaraja HN, Alwan D, Dungan KM. Prevalence, predictors, and outcomes of steroid-induced hyperglycemia in hospitalized patients with hematologic malignancies. Endocrine 2017;56(1):90-97

10 Weiser MA, Cabanillas ME, Konopleva M, et al. Relation between the duration of remission and hyperglycemia during induction chemotherapy for acute lymphocytic leukemia with a hyperfractionated cyclophosphamide, vincristine, doxorubicin, and dexamethasone/methotrexate-cytarabine regimen. Cancer 2004;100(6):1179-1185

11 Hickish T, Astras G, Thomas P, et al. Glucose intolerance during adjuvant chemotherapy for breast cancer. J Natl Cancer Inst 2009;101(7):537

12 Agnoli C, Berrino F, Abagnato CA, et al. Metabolic syndrome and postmenopausal breast cancer in the ORDET cohort: a nested case-control study. Nutr Metab Cardiovasc Dis 2010; 20(1):41-48

13 Lu LJ, Wang RJ, Ran L, et al. On the status and comparison of glucose intolerance in female breast cancer patients at initial diagnosis and during chemotherapy through an oral glucose tolerance test. PLoS One 2014;9(4):e93630

14 Juanjuan L, Wen W, Zhongfen L, et al. Clinical pathological characteristics of breast cancer patients with secondary diabetes after systemic therapy: a retrospective multicenter study. Tumour Biol 2015;36(9):6939-6947

15 Dieli-Conwright CM, Wong L, Waliany S, Bernstein L, Salehian B, Mortimer JE. An observational study to examine changes in metabolic syndrome components in patients with breast cancer receiving neoadjuvant or adjuvant chemotherapy. Cancer 2016;122(17):2646-2653

16 Geer EB, Islam J, Buettner C. Mechanisms of glucocorticoidinduced insulin resistance: focus on adipose tissue function and lipid metabolism. Endocrinol Metab Clin North Am 2014;43(1):75-102

17 Brady VJ, Grimes D, Armstrong T, LoBiondo-Wood G. Management of steroid-induced hyperglycemia in hospitalized patients with cancer: a review. Oncol Nurs Forum 2014;41(6):E355-E365

18 Suh S, Park MK. Glucocorticoid-induced diabetes mellitus: An important but overlooked problem. Endocrinol Metab (Seoul) 2017;32(2):180-189

19 Alberti KG, Zimmet PZ. Definition, diagnosis and classification of diabetes mellitus and its complications. Part 1: diagnosis and classification of diabetes mellitus provisional report of a WHO consultation. Diabet Med 1998;15(7):539-553

20 Khatib OM, ed. Guidelines for the Prevention, Management and Care of Diabetes Mellitus. World Health Organization. Available at: http://applicationsemrowhoint/dsaf/dsa664pdf. Accessed November 20, 2020

21 Diabetes Atlas IDF, Across the Globe. 7th ed. Available at:Accessed November 20, 2020

22 International Diabetes Federation. The International Federation (IDF) Diabetes Atlas. 7th ed. Available at: http:// www.diabetesatlas.org/. Accessed November 20, 2020

23 Lipscombe LL, Chan WW, Yun L, Austin PC, Anderson GM, Rochon PA. Incidence of diabetes among postmenopausal breast cancer survivors. Diabetologia 2013;56(3):476-483

24 Gironés R, Torregrosa D, Díaz-Beveridge R. Comorbidity, disability and geriatric syndromes in elderly breast cancer survivors. Results of a single-center experience. Crit Rev Oncol Hematol 2010;73(3):236-245

25 Padmanabha UR, Nalam U, Badiger S, Nagarajaiah P. Prevalence and risk factors of type 2 diabetes mellitus in the rural 
population of Mangalore, South India. Natl J Community Med 2017;8:456-461

26 Rao CR, Kamath VG, Shetty A, Kamath A. A study on the prevalence of type 2 diabetes in coastal Karnataka. Int J Diabetes Dev Ctries 2010;30(2):80-85

27 Dasappa H, Fathima FN, Prabhakar R, Sarin S. Prevalence of diabetes and pre-diabetes and assessments of their risk factors in urban slums of Bangalore. J Family Med Prim Care 2015;4(3):399-404

28 Awasthi A, Rao CR, Hegde DS, Rao N K. Association between type 2 diabetes mellitus and anthropometric measurements - a case control study in South India. J Prev Med Hyg 2017; 58(1):E56-E62

29 Mohan V, Deepa M, Farooq S, Narayan KM, Datta M, Deepa R. Anthropometric cut points for identification of cardiometabolic risk factors in an urban Asian Indian population. Metabolism 2007;56(7):961-968

30 Anjana RM, Deepa M, Pradeepa R, et al; ICMR-INDIAB Collaborative Study Group. Prevalence of diabetes and prediabetes in 15 states of India: results from the ICMR-INDIAB population-based cross-sectional study. Lancet Diabetes Endocrinol 2017;5(8):585-596 